\title{
Hormonmangel
}

\section{Testosteron schuld an Nykturie?}

— Wenn Männer über 40 nachts häufig zur Toilette müssen, könnte das auch an einem Mangel an Testosteron liegen. In einer aktuellen Studie litten Männer mit einem hohen Serumspiegel des Hormons nur halb so oft an Nykturie wie Altersgenossen mit niedrigen Werten [Chun-Hou Liao et al. Urology 2011; 78:

Drückt mitten in der Nacht die Blase, ist der der Gang zur Toilette unvermeidbar.
631-5]. In der Studie bestimmten Urologen aus Taipeh die Sexualhormonspiegel bei 509 Männern im Alter von 40 bis 80 Jahren (Durchschnittsalter 58 Jahre). Wurden gleichaltrige Männer untersucht, so stellte sich heraus, dass Männer mit hohen Serum-Testosteronwerten nachts deutlich seltener zur Toilette mussten als Männer mit niedrigen Werten: Im Quartil mit den höchsten Testosteronwerten war die Rate für eine Nykturie um $44 \%$ niedriger als im Quartil mit den niedrigsten Werten.

Als Nykturie wurde definiert, wenn die Männer mindestens zweimal pro Nacht urinieren mussten. Einen Zusammenhang zwischen anderen Miktionsbeschwerden und dem Testosteronspiegel konnten die Urologen dagegen ebenso wenig feststellen wie zwischen Prostatavolumen und Testosteronwerten - sofern das Alter der Teilnehmer berücksichtigt wurde. Daraus schließen sie, dass Testosteron unabhängig von anderen Faktoren den nächtlichen Harndrang beeinflusst. Da Testosteron die Vasopressin-Expression und damit die Konzentration des Urins fördert, könnte dies nach Auffassung der Studienautoren eine mögliche Erklärung für den günstigen Effekt sein. Thomas Müller

\section{AMNOG zeigt Wirkung \\ Kassen mit über 2,4 Milliarden im Plus}

— Die gesetzlichen Krankenkassen haben das erste Halbjahr 2011 mit einem Überschuss von 2,417 Milliarden EUR abgeschlossen. Ende Juni 2010 betrug der Überschuss dagegen lediglich 112 Millionen EUR, am Ende des Jahres verbuchten die Kassen gar ein Defizit von 445 Millionen EUR. Nach Angaben des Bundesgesundheitsministeriums liegen die Ausgaben in der zweiten Jahreshälfte generell deutlich höher, deshalb könne für die Monate Juli bis Dezember nicht mit ähnlich hohen Überschüssen wie in den ersten sechs Monaten gerechnet werden.

Besonders stark fällt der Ausgabenrückgang bei Arzneimitteln von minus $6,3 \%$ auf. Der ist vor allem auf den Preisabschlag von $16 \%$ zurückzuführen, den die Arzneihersteller seit August vergangenen Jahres leisten müssen. Darüber hinaus zeigt das ArzneimittelmarktNeuordnungsgesetz (AMNOG), das Anfang dieses Jahres in Kraft getreten ist, offenbar Wirkung.

Keine Rückschlüsse auf die weitere Entwicklung in diesem Jahr lässt nach Angaben des BMG der Zuwachs von 2,3\% bei den Ausgaben für die ambulante Behandlung und um 5,2\% bei den ärztlichen Früherkennungsmaßnahmen zu, da für das erste Halbjahr noch keine Abrechnungsdaten der Kassenärztlichen Vereinigungen vorliegen. Weiter stark nach oben gehen die Ausgaben für Krankengeldzahlungen. Nach zweistelligen Zuwachsraten in den vergangenen Jahren verzeichnen die Krankenkassen jetzt ein Plus von immerhin noch 9,6\%. Ein Grund hier: der starke Anstieg bei lang andauernden psychischen Erkrankungen.

Christiane Badenberg

\section{Schlaganfälle unter Androgendeprivation Widersprüchliche Datenlage}

- Zahlreiche Studien belegen, dass eine langfristige Androgendeprivationstherapie (ADT) eines Prostatakarzinoms neben dem Risiko für Frakturen auch das Risiko für ein metabolisches Syndrom und kardiovaskuläre Krankheiten erhöhen kann. Trotzdem ist der Zusammenhang zwischen ADT und Schlaganfall nach wie vor umstritten.

In einer aktuellen prospektiven Studie aus Taiwan wurde kein erhöhtes Risiko festgestellt. In der Studie wurden 365 Prostatakarzinom-Patienten fünf Jahre lang individuell beobachtet. Insgesamt erlitten 68 Patienten einen Schlaganfall, 17,2\% davon mit ADT und 18,9\% ohne ADT. Dieser Unterschied war nicht signifikant. Daran änderte sich nichts, wenn Alter und andere bekannte Risikofaktoren für einen Schlaganfall berücksichtigt wurden. Auch auf die Genese des Schlaganfalls hatte die ADT keinen Einfluss. In beiden Patientengruppen wurden etwa $50 \%$ der Insulte eindeutig auf eine Ischämie zurückgeführt. Eine Analyse in Abhängigkeit von der Medikation (GnRHAnaloga, orale ADT oder beides) war wegen der geringen Patientenzahlen nicht möglich.

Dieses Ergebnis deckt sich mit den Beobachtungen einer USamerikanischen Studie, wonach weder eine AntiandrogenMonotherapie noch eine Kombinationstherapie mit einem höheren Insultrisiko assoziiert sind. Im Gegensatz dazu wurde jedoch in einer populationsbezogenen Studie aus Schweden ein solcher Zusammenhang nachgewiesen. Die taiwanesischen Forscher empfehlen deswegen weitere populationsbasierte Studien, um das fehlende Schlaganfallrisiko einer ADT zu bestätigen.

Dr. Beate Schumacher 